\title{
Medical Students' Awareness of the Links between Physical Activity and Health
}

\author{
Sandra Mandic ${ }^{1}$, Hamish Wilson², Monika Clark-Grill ${ }^{2}$ and Diana O’Neill ${ }^{3}$
}

Affiliations: ${ }^{1}$ University of Otago, Active Living Laboratory, School of Physical Education, Sport and Exercise Sciences, Dunedin, New Zealand, ${ }^{2}$ University of Otago, Dunedin School of Medicine, Dunedin, New Zealand, ${ }^{3}$ Ministry of Health, Wellington, New Zealand

Correspondence: Sandra Mandic, University of Otago, School of Physical Education, Sport and Exercise Sciences, PO Box 56, Dunedin, New Zealand. E-mail: sandra.mandic@otago.ac.nz

ABSTRACT The effectiveness of physicians in providing advice to patients about physical activity (PA) is influenced by their own understanding of the links between PA and health, as well as by their own PA habits. This study involved pre-clinical medical students in New Zealand, examining their baseline knowledge, skills, and attitudes towards advising patients about PA, as well as eliciting their personal exercise habits. A total of 234 students (age 20.9 2.9 years; $46 \%$ males; participation rate: $99 \%$ ) completed a paper questionnaire assessing their awareness of current PA guidelines, the benefits of PA, their attitudes toward PA advising, perceived competence and importance of PA-advising skills, and personal PA habits. Data were analysed using descriptive statistics. Most students were aware of the benefits of PA and were regularly active. Students perceived PA advising as a high priority in general practice (79\%) but only $37 \%$ felt confident in their ability to provide PA advice. At this point in their training, students considered PA advice to be important $(4.7 \pm 0.8$ out of 6), yet perceived themselves to be only moderately competent in providing patient-oriented exercise prescriptions ( $3.1 \pm 0.8$ out of 6 ). However, students who had regular exercise felt more confident in providing PA advice ( $3.0 \pm 0.9$ vs. $3.3 \pm 0.9, \mathrm{p}=0.009)$. In conclusion, medical students were generally active and had a good understanding of the links between PA and health, but were lacking skills for PA advising. Competence and skills in PA counselling need to be further developed within clinical training as part of an overall curriculum strategy.

KEY WORDS Medical Students, Education, Physical Activity, Exercise Advising.

$@$ MJSSMontenegro

MEDICAL STUDENTS AWARENESS

http://mjssm.me/?sekcija=article\&artid=136

\section{Introduction}

Physical inactivity is one of the major public health problems in the $21^{\text {st }}$ century (Blair, 2009). Challenges in public health associated with sedentary lifestyles and the emerging multiple benefits of regular exercise (Giannuzzi et al., 2003) indicate the importance of preparing future physicians to use exercise as a medical therapeutic option and to provide patient-oriented exercise prescriptions. Furthermore, exercise has intrinsic benefits for students in terms of their own health and wellbeing (Dyrbye, Satele, \& Shanafelt, 2016). Although physicians can be effective in increasing patients' health-promoting behaviours, including exercise (Elley, Kerse, Arroll, \& Robinson, 2003; Harsha, Saywell, Thygerson, \& Panozzo, 1996; Swinburn, Walter, Arroll, Tilyard, \& Russell, 1998), less than half of physicians provide physical activity (PA) screening (Sherman \& Hershman, 1993; Walsh, Swangard, Davis, \& McPhee, 1999) and less than one third of patients report receiving advice about PA within the previous year (Croteau, Schofield, \& McLean, 2006; Eakin, Brown, Marshall, Mummery, \& Larsen, 2004; Wee, McCarthy, Davis, \& Phillips, 1999). Physicians' beliefs (Sherman \& Hershman, 1993), knowledge (Rogers et al., 2006), and attitudes toward PA advising (Rogers et al., 2002), their confidence and prior training in PA advising, and their personal lifestyle (Frank, Hedgecock, \& Elon, 2004; Frank, Rothenberg, Lewis, \& Belodoff, 2000) are the main factors associated with an increased likelihood of physicians' providing PA advice. Limited data from previous studies suggest less than moderate competence and confidence in providing PA advice among medical students (Connaughton, Weiler, \& 
Connaughton, 2001; Vallance, Wylie, \& MacDonald, 2009) and residents (Rogers et al., 2002). Conducted during an introductory study module on lifestyle factors that influence health, this study evaluated the baseline knowledge, skills, and attitudes toward PA advising, as well as the personal PA habits of third-year medical students.

\section{Methods}

Participants

All third-year medical students at the Dunedin School of Medicine, University of Otago, (Dunedin, New Zealand, $\mathrm{n}=237$ ) were offered the opportunity to participate; 234 students (99\%) completed a survey in April 2009. Each participant voluntarily provided written informed consent before participating. Ethics approval was obtained from the University of Otago Human Ethics Committee.

\section{Study design}

Students completed a 15- to 20-minute paper-based questionnaire during tutorial classroom time.

\section{Outcome Measures}

Basic demographic data collected included age, gender, ethnicity, cultural background, and self-reported height and weight.

Assessment of knowledge, skills, and attitudes. Knowledge, skills, and attitudes toward exercise advising were assessed using several questionnaires. Awareness of current physical activity guidelines, publicly available resources on exercise prescription, 'Green Prescription' initiative, and the benefits of exercise were measured using 5-point Likert scales (1 [strongly disagree] to 5 [strongly agree]). The Green Prescription health initiative is a primary health care referral programme in New Zealand (Ministry of Health, 2016). Available since 1998, primary care physicians can refer inactive patients with stable medical conditions to local physical activity providers for free telephone follow-up, one on one, or group support to assist with lifestyle changes (Ministry of Health, 2016). The Green Prescription Initiative was transferred from Sport and Recreation New Zealand (SPARC) to the Ministry of Health in July 2009.

Perceived competence and importance of skills in advising patients about PA were assessed using a validated Exercise and Physical Activity Competence Questionnaire (Connaughton et al., 2001). This questionnaire assessed students' perception of the importance of, and their competence in, performing physical examination, determining maximal heart rate, body mass index, and daily nutritional needs, calculating training heart rate and designing an exercise prescription. The questionnaire contained 12 statements using a 6-point Likerttype scale (for competence: $1=$ not competent to $6=$ very competent; for importance: $1=$ not important to 6 = very important).

The questionnaire assessing beliefs and attitudes toward personal exercise habits as well as exercise advising was modelled on previous work (Abramson, Stein, Schaufele, Frates, \& Rogan, 2000; Keats, Culos-Reed, \& Courneya, 2007). As a part of this questionnaire, students were asked to put themselves in the role of a primary care physician and identify their potential motivations for advising patients about PA, to demonstrate their knowledge of current exercise recommendations, and to identify other health professionals that could assist in providing $\mathrm{PA}$ advice.

Assessment of PA Habits. Students' PA habits were assessed using the New Zealand Physical Activity Questionnaire - short form (Sport and Recreation New Zealand (SPARC), 2004). The questionnaire consists of seven questions related to the frequency and duration of brisk walking as well as other moderate and vigorous physical activities in the previous seven days. Questionnaire data were used to calculate if students met current minimal PA guidelines for adults (at least 150 minutes of moderate intensity PA or at least 75 minutes of vigorous intensity PA in the previous week) (Haskell et al., 2007). The last question referred to stages of change toward adopting regular PA habits. In addition, students were asked to identify their own motivations and barriers to performing regular PA.

\section{Statistical analysis}

Baseline characteristics were described using descriptive statistics. Data are reported as mean \pm SD or frequency (percentage). A P-value less than 0.05 was considered statistically significant. Data were analysed using SPSS statistical software.

\section{Results}

\section{Demographic characteristics}

A total of 234 third-year medical students (age 20.9 \pm 2.9 years; $46 \%$ males; body mass index $22.7 \pm 2.8$ ) completed a set of questionnaires (participation rate: 99\%). Detailed demographic characteristics are presented in Table 1.

\section{Awareness and knowledge of PA guidelines}

Nearly half the students (43\%) were aware of the current New Zealand Physical Activity guidelines for healthy adults (Table 2). Only 2\% of students were aware of the current American College of Sports Medicine (ACSM) 
TABLE 1 Demographic Characteristics

Study sample

$(n=234)$

Gender $[\mathrm{n}(\%)]$

Males $106(46)$

Females $\quad 126(54)$

Age (years)

$20.9 \pm 2.9$

Height $(\mathrm{cm})$

$171 \pm 9$

Weight (kg)

$67 \pm 11$

Body mass index $\left(\mathrm{kg} / \mathrm{m}^{2}\right)$

$22.7 \pm 2.8$

Ethnicity* $[\mathrm{n}(\%)]$

Māori 15 (6)

Chinese $33(14)$

Other $66(28)$

Country of origin ${ }^{\dagger}[n(\%)]$

$\begin{array}{lc}\text { New Zealand } & 122(57) \\ \text { Malaysia } & 25(12) \\ \text { China } & 16(7) \\ \text { Other } & 52(22)\end{array}$

Legend: *Some participants selected belonging to 2 or more ethnic groups; †Other countries of origin include England, Korea, Australia, Brunei, Taiwan, South Africa, South Arabia, and others. Data are missing for 19 participants.

guidelines for exercise in individuals with chronic diseases. The majority of students were aware of the Green Prescription initiative in New Zealand and various benefits of exercise (Table 2).

Only $19 \%$ of students correctly identified a recommended combination of duration, intensity, and frequency of activity to achieve the current minimal exercise recommendations for healthy adults (30 minutes of moderate intensity exercise 5 days per week, equivalent to 150 minutes per week).

TABLE 2 Knowledge of Physical Activity Guidelines, Attitudes towards Physical Activity Advising and Benefits of Physical Activity

\begin{tabular}{|c|c|c|c|c|c|c|}
\hline & $\begin{array}{l}\text { Average } \\
\text { score }\end{array}$ & $\begin{array}{l}\text { Strongly } \\
\text { disagree }\end{array}$ & & & & $\begin{array}{c}\text { Strongly } \\
\text { agree }\end{array}$ \\
\hline & (out of 5) & 1 & 2 & 3 & 4 & 5 \\
\hline \multicolumn{7}{|l|}{ Physical Activity Guidelines and Initiatives } \\
\hline I am aware of the current New Zealand guidelines for physical activity in healthy adults. & $3.1 \pm 1.1$ & $19(8)$ & $55(24)$ & $58(25)$ & $88(38)$ & $12(5)$ \\
\hline $\begin{array}{l}\text { I am aware of the current American College of Sports Medicine guidelines for physical } \\
\text { activity in individuals with chronic diseases. }\end{array}$ & $1.4 \pm 0.6$ & $166(71)$ & $54(23)$ & $9(4)$ & $4(2)$ & $0(0)$ \\
\hline I am aware of "Green Prescription" Initiative in New Zealand. & $4.2 \pm 0.9$ & $7(3)$ & $5(2)$ & $26(11)$ & $89(38)$ & $106(46)$ \\
\hline \multicolumn{7}{|l|}{ Physical Activity Advising } \\
\hline I am confident in my ability to advise patients about physical activity. & $3.2 \pm 0.9$ & $4(2)$ & $47(20)$ & $96(41)$ & $74(32)$ & $12(5)$ \\
\hline I perceive exercise advising as having a high priority in general practice. & $4.4 \pm 4.0$ & $1(0.4)$ & $11(5)$ & $36(16)$ & $108(47)$ & $74(32)$ \\
\hline Exercise advising impacts patients' quality of life. & $4.1 \pm 0.7$ & $1(0.4)$ & $2(1)$ & $40(17)$ & 116(50) & $74(32)$ \\
\hline \multicolumn{7}{|l|}{ Benefits of Physical Activity } \\
\hline Some physical activity is better than none. & $4.8 \pm 0.5$ & $1(0.4)$ & $1(0.4)$ & $1(0.4)$ & 32 (14) & $198(85)$ \\
\hline $\begin{array}{l}\text { For most health outcomes, additional benefits occur as the amount of physical activity } \\
\text { increases through higher intensity, greater frequency, and/or longer duration. }\end{array}$ & $3.9 \pm 0.9$ & $4(2)$ & $13(6)$ & $46(20)$ & 114(49) & $56(24)$ \\
\hline $\begin{array}{l}\text { Both aerobic (endurance) and muscle-strengthening (resistance) physical activity are } \\
\text { beneficial. }\end{array}$ & $4.4 \pm 0.8$ & $1(0.4)$ & $5(2)$ & $18(8)$ & $87(38)$ & $121(52)$ \\
\hline $\begin{array}{l}\text { Health benefits from regular physical activity occur for children and adolescents, young } \\
\text { and middle-aged adults, older adults, and those in every studied racial and ethnic group. }\end{array}$ & $4.7 \pm 0.6$ & $0(0)$ & $3(1)$ & $5(2)$ & $55(24)$ & $169(73)$ \\
\hline The benefits of physical activity far outweigh the possibility of adverse outcomes. & $4.2 \pm 0.8$ & $2(1)$ & $4(2)$ & $39(17)$ & $99(43)$ & $89(38)$ \\
\hline $\begin{array}{l}\text { Adults with chronic conditions obtain important health benefits from regular physical } \\
\text { activity. }\end{array}$ & $4.0 \pm 0.8$ & $2(1)$ & $4(2)$ & $55(24)$ & $100(43)$ & $71(31)$ \\
\hline $\begin{array}{l}\text { When adults with chronic conditions do activity according to their abilities, physical } \\
\text { activity is safe. }\end{array}$ & $4.3 \pm 0.8$ & $1(0.4)$ & $4(1.7)$ & $28(12)$ & $99(43)$ & $100(43)$ \\
\hline $\begin{array}{l}\text { Older adults and people with chronic conditions and symptoms should consult their } \\
\text { health-care provider about the types and amounts of activity appropriate for them. }\end{array}$ & $4.6 \pm 0.7$ & $1(0.4)$ & $4(2)$ & $11(5)$ & $57(25)$ & $160(69)$ \\
\hline
\end{tabular}

Legend: Categorical data presented as [n(\%)]. 


\section{PA advising: Attitudes and competence}

The majority of students perceived PA advising to have a high priority in general practice (79\%) that would impact patients' quality of life (82\%) (Table 2). Only one third of these students felt confident in their ability to provide PA advice (37\%). Overall, most medical students perceived exercise-related prescription to be important (average score: $4.7 \pm 0.8$ out of 6 ), yet they perceived themselves only moderately competent in providing PA advice (average score: $3.1 \pm 0.8$ out of 6 ) (Table 3 , Figure 1).

TABLE 3 Perceived Competence and Importance of Physical Activity Advising

\begin{tabular}{|c|c|c|c|c|}
\hline & $\begin{array}{l}\text { Average } \\
\text { score }\end{array}$ & $\begin{array}{l}\text { Minimally } \\
\text { competent } \\
\text { /important }\end{array}$ & $\begin{array}{l}\text { Moderately } \\
\text { competent } \\
\text { /important }\end{array}$ & $\begin{array}{c}\text { Very } \\
\text { competent } \\
\text { /important }\end{array}$ \\
\hline & (Out of 6 ) & $1-2$ & $3-4$ & $5-6$ \\
\hline Competence & & $\begin{array}{l}\text { Minimally } \\
\text { competent }\end{array}$ & $\begin{array}{l}\text { Moderately } \\
\text { competent }\end{array}$ & $\begin{array}{l}\text { Very } \\
\text { competent }\end{array}$ \\
\hline $\begin{array}{l}\text { I feel competent to conduct a physical exam on a healthy adult to approve that person to begin a } \\
\text { physical activity program. }\end{array}$ & $2.4 \pm 1.1$ & $138(59)$ & $89(38)$ & $7(3)$ \\
\hline I feel competent to determine the maximum heart rate for a healthy adult. & $2.9 \pm 1.5$ & $102(44)$ & $89(38)$ & $43(18)$ \\
\hline I feel competent to determine the daily caloric and nutritional needs of a healthy adult. & $2.9 \pm 1.2$ & $85(36)$ & $130(56)$ & $19(8)$ \\
\hline I feel competent to determine the body mass index for a healthy adult. & $5.8 \pm 0.5$ & $1(0.4)$ & $4(2)$ & $229(98)$ \\
\hline I feel competent to calculate the aerobic training heart rate for a healthy adult. & $2.5 \pm 1.3$ & $134(58)$ & $76(33)$ & $23(10)$ \\
\hline $\begin{array}{l}\text { I feel competent to design a physical activity prescription including frequency, duration and intensity } \\
\text { for a healthy adult }\end{array}$ & $2.3 \pm 1.2$ & $151(65)$ & $69(30)$ & $14(6)$ \\
\hline Average perceived competence & $3.1 \pm 0.8$ & & & \\
\hline Importance & & $\begin{array}{l}\text { Minimally } \\
\text { important }\end{array}$ & $\begin{array}{l}\text { Moderately } \\
\text { important }\end{array}$ & $\begin{array}{l}\text { Very } \\
\text { important }\end{array}$ \\
\hline $\begin{array}{l}\text { It is important to be able to conduct a physical exam on a healthy adult to approve that person to } \\
\text { begin a physical activity program. }\end{array}$ & $5.0 \pm 1.2$ & $18(8)$ & $36(15)$ & $180(77)$ \\
\hline It is important to be able to determine the maximum heart rate for a healthy adult. & $4.3 \pm 1.2$ & $25(11)$ & $105(45)$ & $104(44)$ \\
\hline It is important to be able to determine the daily caloric and nutritional needs of a healthy adult. & $4.9 \pm 1.0$ & $7(3)$ & $66(28)$ & $161(69)$ \\
\hline It is important to be able to determine the body mass index for a healthy adult. & $5.2 \pm 1.0$ & $4(2)$ & $41(18)$ & $188(81)$ \\
\hline It is important to be able to calculate the aerobic training heart rate for a healthy adult. & $4.2 \pm 1.2$ & $17(7)$ & $124(53)$ & $93(40)$ \\
\hline $\begin{array}{l}\text { It is important to be able to design a physical activity prescription including frequency, duration and } \\
\text { intensity for a healthy adult. }\end{array}$ & $4.9 \pm 1.2$ & $15(6)$ & $50(21)$ & $169(72)$ \\
\hline Average perceived importance & $4.7 \pm 0.8$ & & & \\
\hline
\end{tabular}

Legend: Categorical data presented as [n(\%)]; Data were originally collected using a 6-point Likert-scale. Items were collapsed into 3 categories (e.g., minimally competent/important [1 and 2], moderately competent/important [3 and 4], and highly competent/important [5 and 6].

When students were asked to imagine themselves working as primary care physicians in five years, the majority stated that they would counsel patients about PA for improving cardiovascular fitness (97\%), disease prevention (97\%), weight control (96\%), psychological benefits (90\%), and musculoskeletal health $(80 \%)$ (Figure 3).

For more specific exercise advice, nearly half of the students would refer patients to a personal trainer (49\%), physiotherapist (44\%), and/or Green Prescription support (42\%). A smaller percentage of students would seek advice from an exercise physiologist $(21 \%)$ and sports medicine doctor (12\%). Very few students would refer patients to a nurse/nurse practitioner (2\%), other medical doctor (1\%), or other professional (2\%) for exercise advice.

\section{Personal PA habits}

Most students (79\%) were physically active and engaged in $>300$ minutes of moderate intensity PA in a previous week. Only $7 \%$ of students did not meet minimal PA guidelines for healthy adults (minimum 150 minutes of moderate intensity PA in a previous week). Half of the students (51\%) were regularly active in the maintenance stage. On average, students reported engaging in 30 minutes of moderate intensity PA or 20 minutes of vigorous intensity PA on $4.6 \pm 2.1$ days per week.

The total amount of weekly PA was similar between male and female students (males: $744 \pm 706$ minutes; females: $658 \pm 558$ minutes, $\mathrm{p}=0.303$ ), even though female students engaged in less moderate intensity PA in comparison to their male counterparts. Female students reported meeting minimal PA recommendations more frequently in comparison to male students $(4.9 \pm 2.1$ vs. $4.2 \pm 2.1$ days per week, $\mathrm{p}=0.010)$. Self-reported $\mathrm{PA}$ in the previous week was no different when data were analysed according to ethnicity (NZ European versus others) or country of origin (New Zealand versus others) (data not presented). 


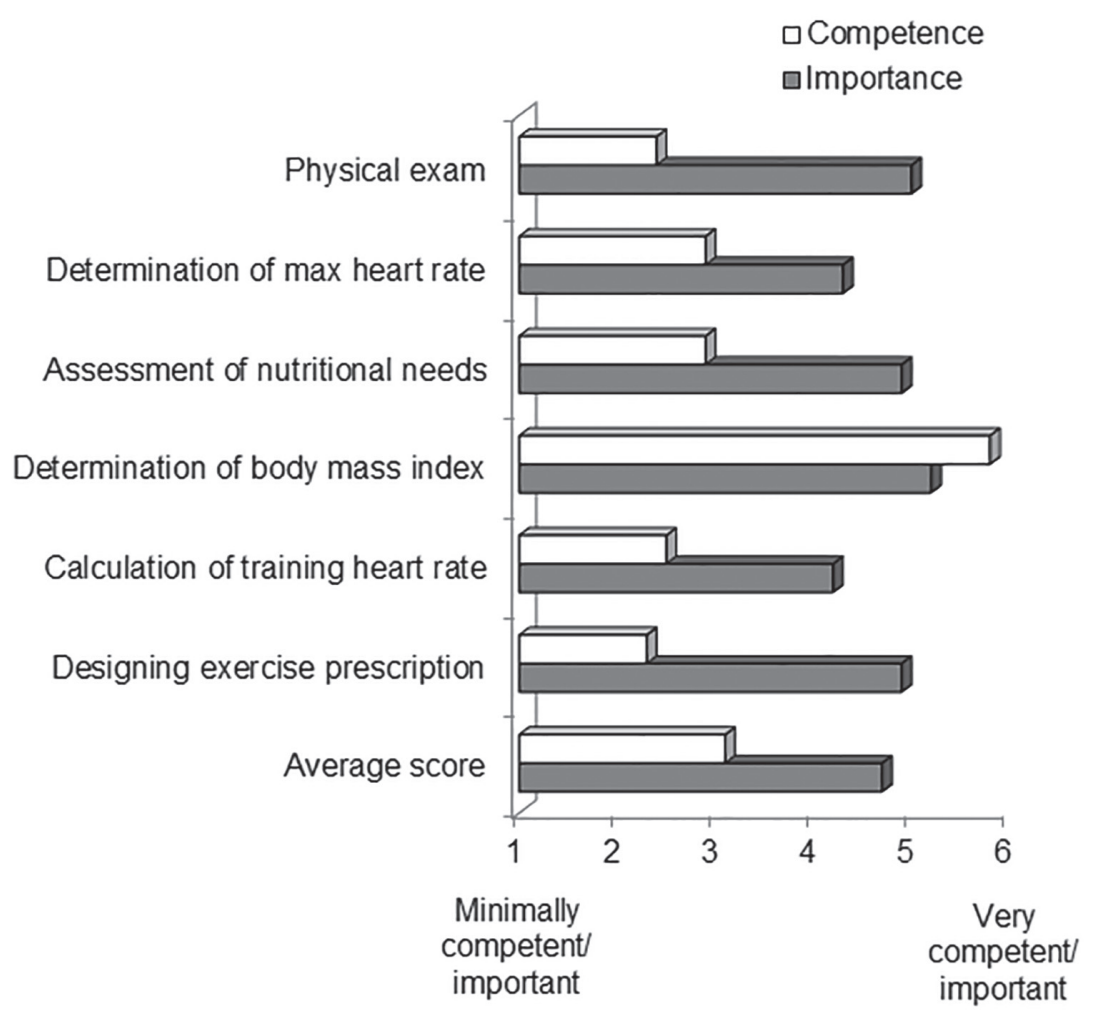

FIGURE 1 Perceived competence in and importance of providing patient-oriented exercise prescription

\section{Motivations and barriers}

Approximately two thirds of students participated in PA to improve their cardiovascular fitness (71\%), general health/disease prevention (72\%), musculoskeletal health (61\%), weight control (60\%), physical appearance (71\%) and psychological benefits (61\%) (Figure 2). In comparison to their male peers, female students were more likely to participate in PA for general health/disease prevention ( $80 \%$ vs. $63 \%, \mathrm{p}=0.003)$, weight control $(81 \%$ vs. $33 \%, \mathrm{p}<0.001)$ and psychological benefits $(67 \%$ vs. $54 \%, \mathrm{p}=0.043)$, and less likely to aim at improving musculoskeletal health ( $53 \%$ vs. $70 \%, \mathrm{p}=0.007)$. The main barriers to students' participation in exercise were lack of time (84\%) and lack of motivation $(61 \%)$ with no significant difference between male versus female students (lack of time, males: $80 \%$, females: $88 \%, p=0.077$; lack of motivation, males: $56 \%$, females: $66 \%$, $\mathrm{p}=0.107)$.

\section{Personal PA habits and PA advising}

Regularly active students in the maintenance stage felt more confident in providing PA advice (3.0 \pm 0.9 vs. $3.3 \pm 0.9, \mathrm{p}=0.009)$ and perceived a greater impact of PA advising on patients' quality of life ( $4.0 \pm 0.7 \mathrm{vs} .3 .3 \pm 0.9$, $\mathrm{p}=0.009$ ) in comparison to their less active peers. Regularly active students felt more competent to determine daily caloric and nutritional needs $(3.2 \pm 1.2$ vs. $2.7 \pm 1.2, \mathrm{p}=0.008)$, and design a detailed exercise prescription for a healthy adult $(2.4 \pm 1.3$ vs. $2.0 \pm 1.2, \mathrm{p}=0.012)$. However, no difference between the groups was found for the overall perception of the importance ( $4.8 \pm 0.8$ vs. $4.7 \pm 0.7, \mathrm{p}=0.195)$ or competence $(3.2 \pm 0.8$ vs. $3.1 \pm 0.8$, $\mathrm{p}=0.385)$ in providing exercise-related prescriptions.

\section{Discussion}

Main findings of the present study are: 1) third year medical students were aware of the current PA guidelines for healthy adults and multiple benefits of PA but were lacking specific knowledge and awareness of the PA guidelines for clinical populations; 2) although the majority of students perceived PA advising to be a high priority in general practice with a positive impact on patients' quality of life, students were lacking confidence and competence in offering client-oriented PA advice; and 3) regularly active students felt more confident but were not more competent in providing exercise-related prescriptions.

Despite their positive attitude toward PA advising, third-year medical students were lacking competence in offering patient-centred exercise prescriptions. Several previous studies examined the competence for prescribing exercise among medical students and resident physicians. Deans and directors of medical schools perceived that $58 \%$ of graduating medical students were competent in conducting a patient evaluation for approving the patient to begin an exercise program, but only $10 \%$ could design a specific exercise program (Connaughton et al., 2001). In contrast, only $29 \%$ of resident physicians felt successful in getting their patients to start exercising and only $28 \%$ felt confident in their skills to prescribe exercise for patients (Rogers et al., 2002). Consistent with a previous study (Vallance et al., 2009), these pre-clinical medical students reported 


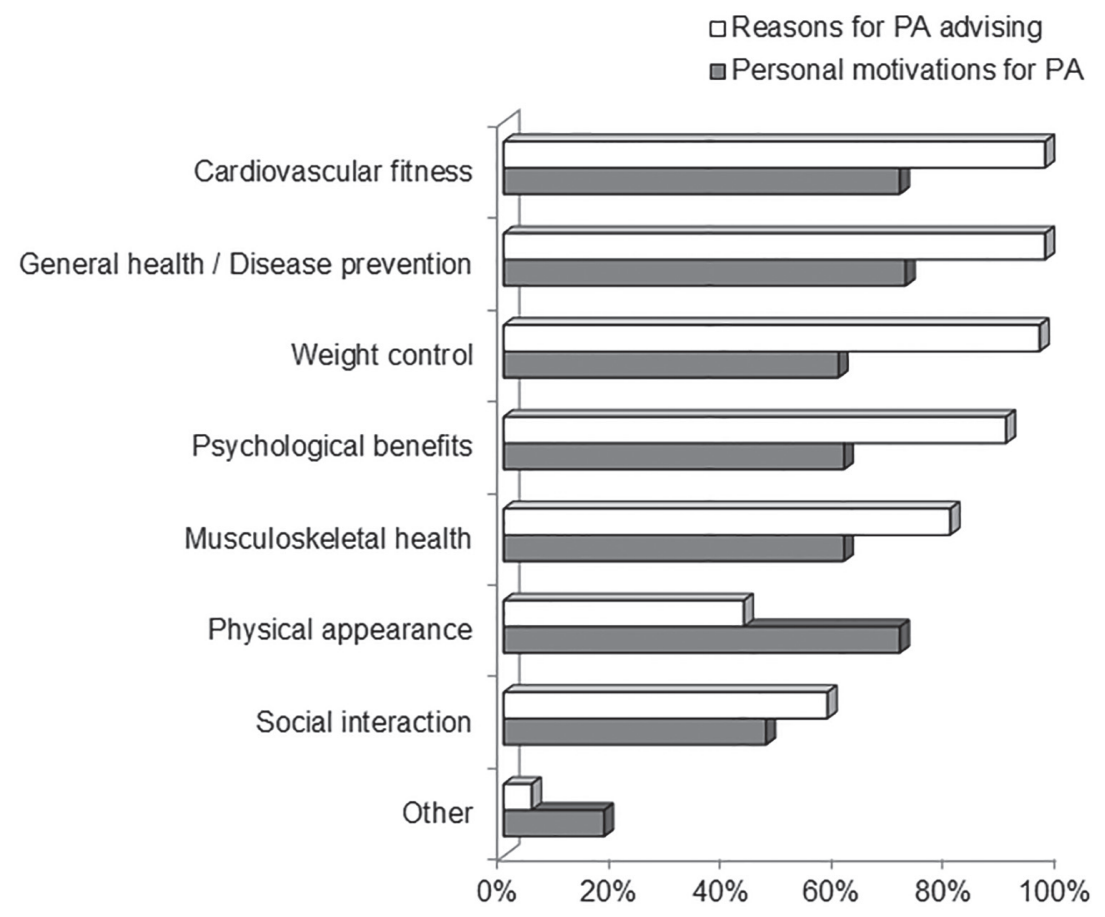

FIGURE 2 Reasons for physical activity advising and personal motivations for engaging in physical activity. PA - physical activity

less than moderate competence for prescribing exercise. In addition, previous studies reported that physicians' confidence in PA-advising skills was significantly influenced by prior training (Rogers et al., 2002). Therefore, it is essential to provide opportunities for medical students to develop effective skills in PA advising as a part of their undergraduate training.

Among multiple factors that contribute to infrequent PA-advising rates, physicians' lifestyles affect both the frequency and quality of the PA advising in their clinical practice (Frank et al., 2004; Frank et al., 2000). Previous studies reported that nearly three quarters of physicians are insufficiently active (Gaertner, Firor, \& Edouard, 1991; Gupta \& Fan, 2009) and almost two thirds of medical residents have less than average fitness (Rogers et al., 2006). A more positive attitude toward health promotion and disease prevention was a significant predictor of fitness among first year medical students (Liang et al., 1993). In the present study, most third year medical students reported meeting minimal PA recommendations in the previous week and half of students were regularly active in the maintenance stage. Despite the main barriers of lack of time and lack of motivation, medical students in the present study were generally physically active. A previous study found that medical students who were achieving the minimum levels of recommended PA perceived higher competence in prescribing patient-oriented exercise prescription (Vallance et al., 2009). In the present study, regularly active medical students felt more confident in providing PA advice and perceived a greater impact of PA advising on patients' quality of life. However, these students did not feel more competent in providing patient-oriented exercise prescriptions in comparison with their less active peers. Similar findings were observed when the results were compared between students who self-reported achieving minimal PA recommendations in the previous week versus those who did not. Therefore, promoting PA among medical students may contribute to improving their confidence in providing PA advice.

With the lack of time for lifestyle advising in primary care practices, future doctors also need to become more aware of other health professionals, such as exercise physiologists, physiotherapists and physical activity providers who can assist them in providing more comprehensive PA advice for their patients. Almost half of the students in the present study would refer patients to a personal trainer, physiotherapist, and/or Green Prescription support, but notably, only one fifth of students would refer their patients to an exercise physiologist. Providing medical students an opportunity to interact with different exercise professionals during their medical training may be an effective way of raising students' awareness of their therapeutic roles and the support they can provide.

The present study adds further evidence that it is essential to raise medical students' awareness and specific knowledge of the current PA guidelines for healthy individuals and clinical populations, to develop their competence and effective skills for PA advising, to raise awareness of the existence of other health professionals who can provide specific PA advice, and to encourage students to be physically active. Increasing PA levels is helpful in many medical conditions. Therefore, taking an exercise history should be a standard feature of routine medical assessment. To achieve these goals, the curriculum on PA assessment and PA advising needs to be comprehensively planned and delivered within undergraduate medical training. 


\section{Study limitations}

The limitations of this study include its cross-sectional design, assessment of students in one medical school, self-reporting of PA habits, and surveying third-year medical students before their exposure to specific training on PA advising. The cross-sectional design prevents claims about causality. Results reported here may not generalizable to other geographic and cultural settings. Although self-reported data on PA may lead to misclassification bias, self-report is a common and convenient strategy (Biddle, Gorely, Pearson, \& Bull, 2011) and a validated questionnaire was used. Knowledge, attitudes, and competence in PA advising and personal PA habits may be different for medical students at later stages of medical training and after exposure to more specific PA-related curricula. Future studies need to examine the outcomes of specific teaching approaches to PA advising on students' attitudes, knowledge, and confidence in providing patient-oriented exercise prescriptions. Similarly, studies need to examine whether such training influences the subsequent rates of PA advising by future physicians in specialist and general practice. In addition, a university culture which encourages PA might also contribute to medical students' greater competence in PA advising.

\section{Conclusion}

Pre-clinical medical students in New Zealand were generally active and had a good understanding of the links between PA and health, but were lacking specific knowledge and skills for PA advising. This was more pronounced among less active students. Future curricula on the benefits of PA should focus on these particular areas and further encourage PA among medical students.

\section{Acknowledgments}

The authors would like to thank Sarah Jutel for administrative support and Sport and Recreation New Zealand (SPARC) for funding the project.

\section{Conflicts of Interest}

The authors have no conflicts of interest. Diana O’Neill worked as a Senior Health Advisor for SPARC at the time of study design and data collection.

\section{REFERENCES}

Abramson, S., Stein, J., Schaufele, M., Frates, E., \& Rogan, S. (2000). Personal exercise habits and counseling practices of primary care physicians: a national survey. Clinical Journal of Sport Medicine, 10(1), 40-48.

Biddle, S. J., Gorely, T., Pearson, N., \& Bull, F. C. (2011). An assessment of self-reported physical activity instruments in young people for population surveillance: Project ALPHA. International Journal of Behavioral Nutrition and Physical Activity, 8, 1-9.

Blair, S. N. (2009). Physical inactivity: the biggest public health problem of the 21 st century. British Journal of Sports Medicine, 43(1), 1-2.

Connaughton, A. V., Weiler, R. M., \& Connaughton, D. P. (2001). Graduating medical students' exercise prescription competence as perceived by deans and directors of medical education in the United States: implications for Healthy People 2010. Public Health Reports, 116(3), 226-234.

Croteau, K., Schofield, G., \& McLean, G. (2006). Physical activity advice in the primary care setting: results of a population study in New Zealand. Australian and New Zealand Journal of Public Health, 30(3), 262-267.

Dyrbye, L. N., Satele, D., \& Shanafelt, T. D. (in press). Healthy Exercise Habits Are Associated With Lower Risk of Burnout and Higher Quality of Life Among U.S. Medical Students. Academic Medicine. doi:10.1097/ ACM.0000000000001540

Eakin, E. G., Brown, W. J., Marshall, A. L., Mummery, K., \& Larsen, E. (2004). Physical activity promotion in primary care: bridging the gap between research and practice. American Journal of Preventive Medicine, 27(4), 297-303.

Elley, C. R., Kerse, N., Arroll, B., \& Robinson, E. (2003). Effectiveness of counselling patients on physical activity in general practice: cluster randomised controlled trial. British Medical Journal, 326(7393), 793.

Frank, E., Hedgecock, J., \& Elon, L. K. (2004). Personal health promotion at US medical schools: a quantitative study and qualitative description of deans' and students' perceptions. BMC Medical Education, 4(1), 29.

Frank, E., Rothenberg, R., Lewis, C., \& Belodoff, B. F. (2000). Correlates of physicians' prevention-related practices. Findings from the Women Physicians' Health Study. Archives of Family Medicine, 9(4), 359-367.

Gaertner, P. H., Firor, W. B., \& Edouard, L. (1991). Physical inactivity among physicians. Canadian Medical Association Journal, 144(10), 1253-1256.

Giannuzzi, P., Mezzani, A., Saner, H., Bjornstad, H., Fioretti, P., Mendes, M., . . Veress, G. (2003). Physical activity for primary and secondary prevention. Position paper of the Working Group on Cardiac Rehabilitation and Exercise Physiology of the European Society of Cardiology. European Journal of Cardiovascular Prevention \& Rehabilitation, 10(5), 319-327.

Gupta, K., \& Fan, L. (2009). Doctors: fighting fit or couch potatoes? British Journal of Sports Medicine, 43(2), 153-154.

Harsha, D. M., Saywell, R. M., Jr., Thygerson, S., \& Panozzo, J. (1996). Physician factors affecting patient willingness to comply with exercise recommendations. Clinical Journal of Sport Medicine, 6(2), 112-118.

Haskell, W. L., Lee, I. M., Pate, R. R., Powell, K. E., Blair, S. N., Franklin, B. A., . . . American Heart, A. (2007). 
Physical activity and public health: updated recommendation for adults from the American College of Sports Medicine and the American Heart Association. Circulation, 116(9), 1081-1093.

Keats, M. R., Culos-Reed, S. N., \& Courneya, K. S. (2007). An examination of the beliefs, attitudes and counselling practices of paediatric oncologists toward physical activity: A provincial survey. Paediatric Child Health, 12(4), 289-293.

Liang, M. T., Dombrowski, H. T., Allen, T. W., Chang, C. O., Andriulli, J., Bastianelli, M., . . Norris, S. D. (1993). Do medical students' knowledge and attitudes about health and exercise affect their physical fitness? The Journal of the American Osteopathic Association, 93(10), 1020-1024, 1028-1032.

Ministry of Health. (2016). Green Prescriptions. Retrieved from http://www.health.govt.nz/our-work/ preventative-health-wellness/physical-activity/green-prescriptions

Rogers, L. Q., Bailey, J. E., Gutin, B., Johnson, K. C., Levine, M. A., Milan, F., . . Sherman, S. E. (2002). Teaching resident physicians to provide exercise counseling: a needs assessment. Academic Medicine, 77(8), 841-844.

Rogers, L. Q., Gutin, B., Humphries, M. C., Lemmon, C. R., Waller, J. L., Baranowski, T., \& Saunders, R. (2006). Evaluation of internal medicine residents as exercise role models and associations with selfreported counseling behavior, confidence, and perceived success. Teaching and Learning in Medicine, 18(3), 215-221.

Sherman, S. E., \& Hershman, W. Y. (1993). Exercise counseling: how do general internists do? Journal of General Internal Medicine, 8(5), 243-248.

Sport and Recreation New Zealand (SPARC). (2004). The New Zealand Physical Activity Questionnaires: Report on the validation and use of the NZPAQ-LF and NZPAQ-SF self-report physical activity survey instruments. Wellington.

Swinburn, B. A., Walter, L. G., Arroll, B., Tilyard, M. W., \& Russell, D. G. (1998). The green prescription study: a randomized controlled trial of written exercise advice provided by general practitioners. American Journal of Public Health, 88(2), 288-291.

Vallance, J. K., Wylie, M., \& MacDonald, R. (2009). Medical students' self-perceived competence and prescription of patient-centered physical activity. Preventive Medicine, 48(2), 164-166.

Walsh, J. M., Swangard, D. M., Davis, T., \& McPhee, S. J. (1999). Exercise counseling by primary care physicians in the era of managed care. American Journal of Preventive Medicine, 16(4), 307-313.

Wee, C. C., McCarthy, E. P., Davis, R. B., \& Phillips, R. S. (1999). Physician counseling about exercise. JAMA, 282(16), 1583-1588. 